\title{
STUDY TO COMPARE THE THERAPEUTIC EFFICACY OF N-ACETYL CYSTEINE AND COMBINATION OF N-ACETYL CYSTEINE AND TAURINE IN PROTEINURIA IN DIABETIC NEPHROPATHY
}

\author{
AKHILESH KUMAR SINGH, PRABHAT AGARWAL, SAURABH KAUSHIK*
}

PG Department of Medicine, Sarojini Naidu Medical College, Agra, Uttar Pradesh, India. Email: drsaurabhkaushik@gmail.com Received: 26 September 2016, Revised and Accepted: 01 November 2016

\section{ABSTRACT}

Objective: Proteinuria is an established risk factor for progressive damage of kidney. This proteinuria can be effectively controlled by drugs that interrupt the renin-angiotensin-aldosterone system. However, the efficacy of N-acetyl cysteine (NAC) and taurine in prevention of diabetic nephropathy (DN) is uncertain. The role of NAC and taurine in reducing of proteinuria in patients with DN was studied.

Methods: The present study was undertaken in the Postgraduate Department of Medicine of S.N. Medical College, Agra. A total of 60 patients of diabetes mellitus with evidence of nephropathy were included in the study. Twenty patients were given placebo medication (Group P), 20 patients received NAC (Group A), and remaining 20 received a combination of NAC and taurine (Group B). Each group was further subdivided according to the urinary albumin excretion in $24 \mathrm{hrs}$. Subgroup 1 - Urinary albumin excretion between 30 and $300 \mathrm{mg} / 24 \mathrm{hrs}$. Subgroup 2 - Urinary albumin excretion $>300 \mathrm{mg} / 24 \mathrm{hrs}$. The stastical analysis used Student's $t$-test.

Results: On comparison, in both microalbuminuria and macroalbuminuria patients divided into three groups; the difference in magnitude of increase in proteinuria (after NAC, NAC with taurine, and placebo administration) over 24 weeks of the study period was statistically insignificant.

Conclusions: In this study, there was no significant difference of proteinuria before and after NAC administration, and also in our study, there was no significant difference of proteinuria before and after taurine administration.

Keywords: Albuminuria, Diabetic nephropathy, N-acetyl cysteine, Taurine.

(C) 2017 The Authors. Published by Innovare Academic Sciences Pvt Ltd. This is an open access article under the CC BY license (http://creativecommons. org/licenses/by/4. 0/) DOI: http://dx.doi.org/10.22159/ajpcr.2017.v10i2.15369

\section{INTRODUCTION}

Diabetic nephropathy (DN) is the leading cause of mortality and morbidity in diabetic patients. It is also the leading cause of end-stage renal disease (ESRD). The proportion of diabetes-related ESRD among all cases of ESRD is reported to be about $25-55 \%$. The pathological abnormality found in DN includes mesangial expansion, basement membrane thickening, glomerulo- and arteriosclerosis, changes in endothelial and tubular cells, podocyte abnormalities, and interstitial inflammation [1-3]. However, the excessive deposition of extracellular matrix (ECM) proteins in mesangium and basement membrane of glomerulus are the earliest morphological changes and typical hallmarks of DN $[4,5]$.

The earliest clinical evidence of DN is microalbuminuria [6]. Glomerular hemodynamic changes such as hyperperfusion and hyperfiltration cause leakage of albumin from glomerulus into Bowman's space [7]. There are many factors including nitric oxide (NO), insulin-like growth factors, angiotensin II, vascular endothelial growth factor, transforming growth factor $\beta_{1}$ (TGF $\beta_{1}$ ), cytokines, and reactive oxygen species (ROS) have been implicated in pathogenesis of DN. Hyperglycemia induces endothelial apoptotic cell death and vascular endothelial dysfunction (VED) [8]. More precisely, hyperglycemia leads to production of ROS, which in turn causes downregulation of expression of NO synthase [8]. VED results in decreased production of NO and increased production of ROS. It is well known that blockage of renin angiotensin aldosterone system prevents microalbuminuria progression and ultimately chronic renal damage [9].

Oxidative stress is a well-known phenomenon in pathogenesis of DN. It has been seen that antioxidants such as vitamin $\mathrm{E}$, vitamin $\mathrm{C}$, and statins reduce proteinuria in diabetic patients. Human studies on $\mathrm{N}$-acetyl cysteine (NAC) as an antioxidative agent are limited; the majority of studies are on animal models. NAC in experimental models has revealed a reduction in ischemia in acute kidney damages, improved glomerular filtration rate, and shortened recovery periods [10-13]. Studies of human beings on the role of NAC in the treatment of DN and proteinuria are not frequent and findings are controversial [14-17].

Taurine (2-aminoethanesulfonic acid) is considered an endogenous antioxidant. Recent studies have shown that taurine protects renal tissues against damage from oxidative stress [18-21]. To further investigate, we studied the therapeutic efficacy of NAC and taurine in proteinuria in DN.

\section{METHODS}

The present study was undertaken in the Postgraduate Department of Medicine of S.N. Medical College, Agra. A total of 60 patients of diabetes mellitus with evidence of nephropathy were included in the study. Patients with known hypersensitivity to NAC/taurine, with chronic liver disease, patients with non-diabetic nephrotic cause of proteinuria, patients with acid peptic disease, pregnant and lactating women, patients with uncontrolled hypertension, patients with coronary artery disease, patients who have had cerebrovascular accident within last 1 year, patients with evidence of heart failure, and patients taking angiotensin-converting enzyme (ACE) inhibitors, angiotensin receptor blockers (ARBs), and calcium channel blockers were excluded from the study. Ethical clearance was taken from Ethical Committee. After taking informed consent, three groups were made according to medication used. Twenty patients were given placebo medication (Group P), 20 patients received NAC (Group A), and remaining 20 received a combination of NAC and taurine (Group B). 
- $\quad$ Group P - Received placebo

- Group A - Received NAC

- Group B - Received combination of NAC and taurine.

Each group was further subdivided according to the urinary albumin excretion in $24 \mathrm{hrs}$

- Subgroup 1 - Urinary albumin excretion between 30 and $300 \mathrm{mg} / 24 \mathrm{hrs}$

- Subgroup 2 - Urinary albumin excretion $>300 \mathrm{mg} / 24 \mathrm{hrs}$

The enrolled patients were subjected to detailed clinical examination. Cases were subjected to the following investigations:

Hemogram, blood sugar (fasting and postprandial), kidney function test, liver function test, urine analysis, 24 hrs urine protein, fundus examination, ultrasonography for kidney size, and echogenicity. Patients were followed up at 24 weeks. Tight glycemic control was maintained in all groups, and drug compliance was assured.

Table 1: Age distribution of cases

\begin{tabular}{llll}
\hline Age range (in years) & Group P & Group A & Group B \\
\hline $25-35$ & 2 & 2 & 0 \\
$36-45$ & 7 & 8 & 8 \\
$46-55$ & 8 & 10 & 12 \\
$56-65$ & 3 & 0 & 0 \\
Total & 20 & 20 & 20 \\
\hline
\end{tabular}

Table 2: Sex distribution of cases

\begin{tabular}{llll}
\hline \multirow{2}{*}{ Sex } & N (\%) & & \\
\cline { 2 - 4 } & Group P & Group A & Group B \\
\hline Male & $12(60.00)$ & $15(75)$ & $14(70)$ \\
Female & $8(40.00)$ & $5(25)$ & $6(30)$ \\
Total & $14(100)$ & $26(100)$ & $20(100)$ \\
\hline
\end{tabular}

\section{RESULTS}

A maximum number of cases were in the age group of 46-55 years (Table 1).

There is male preponderance in all the three groups. This can be explained by as males are attending the outpatient department more than females in numbers (Table 2).

In patients withmicroalbuminuriaand receivingplacebo drug(GroupP1), mean baseline value of microalbuminuria was $222.25 \pm 66.25 \mathrm{mg} / 24 \mathrm{hrs}$, and at 24 weeks, it was $251.50 \pm 55.58 \mathrm{mg} / 24 \mathrm{hrs}$. Percentage increase in mean value of microalbuminuria at 24 weeks from baseline $(13.16 \%)$ was significant. In patients with microalbuminuria and receiving NAC (Group A1), the mean baseline value of microalbuminuria was $209.86 \pm 64.32 \mathrm{mg} / 24 \mathrm{hrs}$, and at 24 weeks, it was $229.29 \pm 60.52 \mathrm{mg} / 24$ hrs. Percentage increase in value at 24 weeks was $9.26 \%$ and that was significant. In Group B1, in which the patients were receiving a combination of NAC and taurine, mean baseline microalbuminuria was $225.67 \pm 49.60 \mathrm{mg} / 24 \mathrm{hrs}$, and at 24 weeks, it was $244.33 \pm 53.61 \mathrm{mg} / 24$ hrs. Percentage increase in mean value of the albuminuria as compared to baseline value was $8.27 \%$ and this increase in mean value was significant (Table 3).

At 24 week, comparison of decrease in magnitude of microalbuminuria in all three groups (P1, A1, and B1) was insignificant statistically.

In patients with overt proteinuria receiving placebo (Group P2), mean baseline value was $609.67 \pm 147.03 \mathrm{mg} / 24 \mathrm{hrs}$ and at 24 weeks was $657.33 \pm 154.20$. The percentage increase in overt proteinuria at 24 weeks was $7.82 \%$. This increase in proteinuria was significant at 24 weeks. In patients with overt proteinuria receiving NAC (Group A2), mean baseline value was $628.67 \pm 200.83 \mathrm{mg} / 24 \mathrm{hrs}$ and 24 weeks was $671.83 \pm 222.55$. The percentage increase in overt proteinuria at 24 weeks was $6.87 \%$. In patients with overt proteinuria receiving a combination of NAC and taurine (Group B2), mean baseline value was $642.75 \pm 205.53$ and at 24 weeks was $685 \pm 218.57 \mathrm{mg} / 24 \mathrm{hrs}$.

Table 3: Microalbuminuria at baseline and 24 weeks (Subgroup 1 in all these groups)

\begin{tabular}{|c|c|c|c|c|c|}
\hline Group & Subgroup & Number & $\begin{array}{l}24 \text { hrs proteinuria } \\
\text { baseline (mg/24 hrs) }\end{array}$ & $\begin{array}{l}24 \text { hrs proteinuria at } \\
24 \text { weeks (mg/24 hrs) }\end{array}$ & $\%$ change over baseline \\
\hline $\mathrm{P}$ & 1 & 11 & $222.25 \pm 66.25$ & $251.5 \pm 55.58$ & 13.16 \\
\hline A & 1 & 8 & $209.86 \pm 64.32$ & $229.29 \pm 60.52$ & 9.26 \\
\hline B & 1 & 12 & $225.67 \pm 49.60$ & $244.33 \pm 53.61$ & 8.27 \\
\hline \multirow{2}{*}{\multicolumn{2}{|c|}{ Subgroups 1}} & \multicolumn{2}{|c|}{$24 \mathrm{hrs}$ proteinuria baseline $(\mathrm{mg} / 24 \mathrm{hrs})$} & & $\begin{array}{l}24 \text { hrs proteinuria at } 24 \text { weeks (mg/24 } \\
\text { hrs) }\end{array}$ \\
\hline & & t-value & p value & t-value & $p$ value \\
\hline \multirow{3}{*}{\multicolumn{2}{|c|}{$\begin{array}{l}\text { Groups } P \text { and } A \\
\text { Groups } P \text { and B } \\
\text { Groups A and B }\end{array}$}} & 0.4093 & $0.4093^{\mathrm{NS}}$ & 0.8282 & $0.421^{\mathrm{NS}}$ \\
\hline & & -0.1392 & $0.8908^{\mathrm{NS}}$ & 0.3275 & $0.7466^{\mathrm{NS}}$ \\
\hline & & -0.5883 & $0.5669^{\mathrm{NS}}$ & -0.5695 & $0.5781^{\mathrm{NS}}$ \\
\hline
\end{tabular}

NS: The two samples are not significantly different

Table 4: Overt albuminuria/24 hrs at baseline and at 24 weeks (Subgroup in all these groups)

\begin{tabular}{|c|c|c|c|c|c|}
\hline Group & Subgroup & $\mathbf{N}$ & $\begin{array}{l}\text { Baseline } \\
\text { proteinuria (mg/24 hrs) }\end{array}$ & $\begin{array}{l}\text { Proteinuria at } \\
24 \text { weeks (mg/24 hrs) }\end{array}$ & $\%$ Change over baseline \\
\hline $\mathrm{P}$ & 2 & 9 & $609.67 \pm 147.03$ & $657.33 \pm 154.20$ & 7.82 \\
\hline A & 2 & 12 & $628.67 \pm 200.83$ & $671.83 \pm 222.55$ & 6.87 \\
\hline B & 2 & 8 & $642.75 \pm 205.53$ & $685.00 \pm 218.57$ & 6.57 \\
\hline \multirow{2}{*}{\multicolumn{2}{|c|}{ Subgroups 2}} & \multicolumn{2}{|c|}{ Proteinuria baseline (mg/24 hrs) } & & Proteinuria at 24 weeks $(\mathrm{mg} / 24 \mathrm{hrs})$ \\
\hline & & t-va & p value & t-value & p value \\
\hline \multirow{3}{*}{\multicolumn{2}{|c|}{$\begin{array}{l}\text { Group P and A } \\
\text { Group P and B } \\
\text { Group A and B }\end{array}$}} & -0.2 & $0.8166^{\mathrm{NS}}$ & -1762 & $0.862^{\mathrm{NS}}$ \\
\hline & & -0.3 & $0.7122^{\mathrm{NS}}$ & -0.2981 & $0.7705^{\mathrm{NS}}$ \\
\hline & & -0.1 & $0.8816^{\mathrm{NS}}$ & -0.1311 & $0.8974^{\mathrm{NS}}$ \\
\hline
\end{tabular}

NS: The two samples are not significantly different 
The percentage increase at 24 weeks was $6.57 \%$. This increase in proteinuria was significant at 24 weeks.

On comparing, decrease in overt albuminuria at 24 weeks in each group (P2, A2, and B2) was statistically insignificant (Table 4).

\section{DISCUSSION}

It is well established that ACE inhibitors and ARBs halt the progression of proteinuria in diabetic patients. Studies have shown that oxidative stress leads to progression of glomerulonephritis by producing nicotinamide adenine dinucleotide phosphate oxidase [20,21]. NAC has considerable effects on free radicals and oxidative stress. Plasminogen inhibitors have a role in ECM fixing. Hyperglycemia promotes plasminogen inhibitors and induces free radicals. This phenomenon damages glomeruli in diabetic patients. Lee et al. in their study have shown that NAC reduces plasminogen inhibitor levels and decreases free oxygen radicals [22]. Trend toward using NAC due to its antioxidant role has been increasing [23]. Clinically, only one study has been done to demonstrate the therapeutic effects of NAC on proteinuria in diabetic patients [24]. In this study, there was no significant difference of proteinuria before and after NAC administration.

In a study on diabetic rats, taurine, an endogenous antioxidant, has suppressed further increase in urinary protein excretion. In this study, it was also seen that taurine reduced mesangial extracellular matrix expansion and TGF $\beta$ expression in renal glomeruli. TGF $\beta$ has been postulated to play an important role in mesangial expansion by accelerating ECM production in diabetic renal tissues. Studer et al. [25] had shown that taurine inhibited high glucose-related overexpression of TGF $\beta$ in cultured mesangial cells in similar fashion to that of NAC. Evidence of beneficial effects of taurine in DN has been accumulating. Ha et al. [19] reported that taurine suppresses the expression of TGF $\beta$ at both mRNA and protein levels. Furthermore, Trachtman et al. [21] showed that taurine decreases immunohistochemical staining of Type IV collagen in glomeruli of diabetic rats. However, in our study, there was no significant difference of proteinuria before and after taurine administration.

\section{REFERENCES}

1. Hasslacher C, Ritz E, Wahl P, Michael C. Similar risks of nephropathy in patients with type I or type II diabetes mellitus. Nephrol Dial Transplant 1989;4:859-63.

2. Berger M, Mönks D, Wanner C, Lindner TH. Diabetic nephropathy: An inherited disease or just a diabetic complication? Kidney Blood Press Res 2003;26:143-54

3. Parving HH. Diabetic nephropathy: Prevention and treatment. Kidney Int 2001;60:2041-55

4. Wolf G. New insights into the pathophysiology of diabetic nephropathy: From haemodynamics to molecular pathology. Eur J Clin Invest 2004;34:785-96

5. Mason RM, Wahab NA. Extracellular matrix metabolism in diabetic nephropathy. J Am Soc Nephrol 2003;14:1358-73.

6. Shumway JT, Gambert SR. Diabetic nephropathy-pathophysiology and management. Int Urol Nephrol 2002;34:257-64

7. Wolf G, Ziyadeh FN. Cellular and molecular mechanisms of proteinuria in diabetic nephropathy. Nephron Physiol 2007;106:26-31.
8. Balakumar P, Chakkarwar VA, Krishan P, Singh M. Vascular endothelial dysfunction: A tug of war in diabetic nephropathy? Biomed Pharmacother 2009;63:171-9.

9. Brown NJ, Vaughan DE. Angiotensin-converting enzyme inhibitors. Circulation 1998;97:1411-20.

10. Stevens MA, Mccullough PA, Tobin KJ, Speck JP, Westveer DC, Guido-Allen DA, et al. A prospective randomized trial of prevention measures in patients at high risk for contrast nephropathy: Results of the P.R.I.N.C.E. study. Prevention of radiocontrast induced nephropathy clinical evaluation. J Am Coll Cardiol 1999;33:403-11.

11. Gare M, Haviv YS, Ben-Yehuda A, Rubinger D, Bdolah-Abram T, Fuchs S, et al. The renal effect of low-dose dopamine in highrisk patients undergoing coronary angiography. J Am Coll Cardiol 1999;34:1682-8

12. Hall KA, Wong RW, Hunter GC, Camazine BM, Rappaport WA, Smyth $\mathrm{SH}$, et al. Contrast-induced nephrotoxicity: The effects of vasodilator therapy. J Surg Res 1992;53:317-20.

13. Solomon R, Werner C, Mann D, D'Elia J, Silva P. Effects of saline, mannitol, and furosemide to prevent acute decreases in renal function induced by radiocontrast agents. N Engl J Med 1994;331:1416-20.

14. Seyss C, Foote EF. Calcium-channel blockers for prophylaxis of radiocontrast-associated nephrotoxicity. Ann Pharmacother $1995 ; 29: 187-8$.

15. Abizaid AS, Clark CE, Mintz GS, Dosa S, Popma JJ, Pichard AD, et al. Effects of dopamine and aminophylline on contrast-induced acute renal failure after coronary angioplasty in patients with pre-existing renal insufficiency. Am J Cardiol 1999;83:260-3.

16. Conessa EL, Valero F, Nadal JC, Fenoy FJ, López B, Arregui B, et al. N-acetyl-L-cysteine improves renal medullary hypoperfusion in acute renal failure. Am J Physiol Regul Integr Comp Physiol 2001;281:R730-7.

17. DiMari J, Megyesi J, Udvarhelyi N, Price P, Davis R, Safirstein R. $\mathrm{N}$-acetyl cysteine ameliorates ischemic renal failure. Am J Physiol 1997;272:F292-8

18. Hamada Y, Miyata S, Nii-Kono T, Kitazawa R, Kitazawa S, Higo S, et al. Overexpression of thioredoxin1 in transgenic mice suppresses development of diabetic nephropathy. Nephrol Dial Transplant 2007;22:1547-57.

19. Ha H, Yu MR, Kim KH. Melatonin and taurine reduce early glomerulopathy in diabetic rats. Free Radic Biol Med 1999;26(7-8):944-50.

20. Trachtman H, Del-Pizzo R, Futterweit S, Levine D, Rao PS, Valderrama E, et al. Taurine attenuates renal disease in chronic puromycin aminonucleoside nephropathy. Am J Phsiol 1992;262:F117-23.

21. Trachtman H, Futterweit S, Maesaka J, Ma C, Valderrama E, Fuchs A, et al. Taurine ameliorates chronic streptozocin-induced diabetic nephropathy in rats. Am J Physiol 1995;269:F429-38.

22. Lee EA, Seo JY, Jiang Z, Yu MR, Kwon MK, Ha H, et al. Reactive oxygen species mediate high glucose-induced plasminogen activator inhibitor-1 up-regulation in mesangial cells and in diabetic kidney. Kidney Int 2005;67:1762-71.

23. Ng TM, Shurmur SW, Silver M, Nissen LR, O'Leary EL, Rigmaiden RS, et al. Comparison of N-acetylcysteine and fenoldopam for preventing contrast-induced nephropathy (CAFCIN). Int J Cardiol 2006 24;109:322-8.

24. Saklayen MG, Yap J, Vallyathan V. Effect of month-long treatment with oral $\mathrm{N}$-acetylcysteine on the oxidative stress and proteinuria in patients with diabetic nephropathy: A pilot study. J Investig Med 2010;58:28-31.

25. Studer RK, Craven PA, DeRubertis FR. Antioxidant inhibition of protein kinase $\mathrm{C}$-signaled increases in transforming growth factor-beta in mesangial cells. Metabolism 1997;46:918-25. 